\title{
STUDI DESKRIPTIF TEMPAT WUDHU ERGONOMI PADA LANJUT USIA (LANSIA) DI PANYABUNGAN MANDAILING-NATAL
}

\author{
Yuli Aisyah Putri ${ }^{1}$, Tri Niswati Utami ${ }^{2}$ \\ ${ }^{1,2}$ Universitas Islam Negeri Sumatera Utara, Medan, Indonesia \\ Email: putriyuliaisyah@gmail.com,triniswatiutami@uinsu.ac.id
}

\begin{abstract}
The level of comfort in performing ablution movements is very dependent on the shape of the ablution position, especially the height of the faucet and the movement position of the person standing or sitting for ablution, as well as the type of person who performs ablution. Purpose: to describe and describe the design of an ergonomic ablution place for the elderly in Panyabungan, Mandailing-Natal. Methods this study uses a qualitative method. The research approach used is a case study. Research informants were determined by purposive sampling consisting of key informants 3 elderly people, and 1 person from the mosque BKM. Supporting informants consist of 1 community leader, so the total informants are 5 people. Data analysis was collected by free-guided interviews using the Miles and Huberman technique. Processing using ATLAS.ti9 software. Result analysis of the data obtained that comfort affects the need for ablution facilities can be seen based on the value of the co-occurrence correlation coefficient (0.30). Based on ATLAS.ti9 analysis, 5 themes were obtained, namely: comfort, complaints, ablution time, frequency of use, and facility needs. Conclusion From the analysis it was found that the ablution place with a sitting position had the best value in this study, the need for facilities affected the comfort of ablution in the elderly, the floor in the ablution place was made flush with the road.
\end{abstract}

Keywords: Ergonomics, elderly, convenience, ablution place, descriptive study.

\section{PENDAHULUAN}

Proses penuaan pada lansia terjadi seiring bertambahnya umur, dalam hal ini dapat menimbulkan permasalahn terkait aspek kesehatan, ekonomi, maupun sosial. Oleh karena itu peningkatan pelayanan kesehatan terhadap lanjut usia dapat meningkatkan kualitas hidupnya (Festi, 2018). Peraturan Pemerintah Republik Indonesia Nomor 43 tahun 2004 lanjut usia adalah seseorang yang telah mencapai usia 60 tahun ke atas. Lanjut usia mengalami beberapa masalah kesehatan, masalah ini berawal dari kemunduran sel-sel tubuh, sehingga fungsi dan daya tahan tubuh menurun serta faktor risiko terhadap penyakit pun meningkat (Kementerian Kesehatan RI, 2017).

Berdasarkan data proyeksi penduduk di Indonesia pada tahun 2017, diperkirakan terdapat 23,66 juta jiwa penduduk lansia $(9,03 \%)$. Jumlah ini terus meningkat pada tahun berikutnya dengan prediksi tahun 2020 mencapai 27,08 juta jiwa, tahun 2025 menjadi 33,69 juta jiwa, tahun 2030 mencapai 40,95 juta jiwa dan tahun 2035 diperkirakan mencapai 48,19 juta jiwa (Kementerian Kesehatan RI, 2017). 
Lansia mengalami periode kemunduran dalam berbagai aspek, terkait dengan penurunan kondisi psikis, sosial, dan fisik. Penurunan kemampuan lansia mengakibatkan terbatasnya aktifitas yang dapat dilakukan sehingga lansia memiliki banyak waktu luang hingga 10 jam per hari. Waktu luang tersebut dapat dimanfaatkan dengan melakukan berbagai aktifitas yang berdampak positif terutama bagi kesehatan lansia baik fisik maupun psikis. Aktifitas tersebut dapat berupa aktifitas fisik ringan atau aktifitas yang dapat menstimulus otak yang dapat mempertahankan kognitif, motorik, maupun sensorik lansia (Isywari \& Iskandriawan, 2016).

Akibat penurunan kondisi fisik, lansia rentan terhadap berbagai penyakit degeneratif, dengan demikian lansia mengalami penurunan pada berbagai sistem tubuh, salah satunya adalah gangguan dan penurunan fungsi sistem muskuloskletal (Azizah, 2011).

Berdasarkan penurunan kemampuan fisik pada lansia maka fasilitas yang dibutuhkan harus disesuaikan dengan kemampuan lansia. Fasilitas yang nyaman, aman dan mudah digunakan untuk mencegah kecelakaan pada lansia saat beraktivitas. Fasilitas tersebut harus dapat mendukung segala keterbatasan lansia agar mereka dapat beraktivitas seperti biasa tanpa menyebabkan kecelakaan.
Salah satu yang sering dipergunakan kaum lansia di masjid adalah tempat wudhu. Tempat wudhu ini berkaitan dengan pelaksanaan ibadah, yaitu sebagai tempat melakukan aktivitas wudhu sebelum melakukan ibadah shalat. Tempat wudhu harus memiliki intensitas cahaya yang baik agar tidak menabrak bendabenda di sekitar. Ketinggian lantai dengan kran harus memiliki ketetapan yang baik agar dapat di gunakan lansia saat melakukan gerakan wudhu kaki untuk menjaga keseimbangan tubuh. Dalam hal ini pilar sangat dibutuhkan di tempat wudhu untuk meminimalisirkan kecelakaan seperti terjatuhnya lansia saat membasuh kaki akibat keramik atau lantai yang licin.

Penelitian sebelumnya, Suparwoko (2016) telah membuat standar dimensi untuk perancangan fasilitas wudhu dengan pertimbangan ergonomi terutama di masjid. Hasil rancangannya berupa standar dimensi yang sekiranya akan memudahkan para lansia untuk mengambil wudhu.

Tingkat kenyamanan dalam melakukan gerakan wudhu sangat bergantung pada bentuk posisi wudhu, terutama ketinggian keran dan posisi pergerakan orang yang berdiri atau duduk untuk berwudhu, serta tipe orang yang melakukan aktivitas wudhu. Menurut pengamatan awal di banyak masjid di Panyabungan Mandailing-Natal, beberapa tempat wudhu 
yang digunakan masyarakat berbeda-beda, di antaranya cukup tinggi sehingga memengaruhi kenyamanan lansia pada saat berwudhu. Oleh karena itu, untuk mendapatkan desain tempat wudhu yang nyaman, diperlukan studi yang cermat untuk membandingkan bentuk tempat wudhu yang ergonomi.

Ergonomi menjadi isu utama dalam interaksi antara manusia dengan lingkungan. Interaksi manusia dengan lingkungannya dimulai dengan interaksi terhadap benda penyusun dimensi semisal panjang, lebar, waktu, beban tugas dan lain-lain hingga interaksi terhadap benda kongkrit seperti pakaian, alat kerja dan lain-lain (Sugiono et al., 2018). Ergonomi dilaksanakan dengan tujuan untuk meningkatkan efektifitas dan efisiensi pekerjaan, baik dalam bidang mempernyaman penggunaan, mengurangi kesalahan dan meningkatkan produktifitas.

Gangguan atau cedera saat melakukan aktivitas berwudhu merupakan masalah yang menjadi dasar latar belakang penelitian yang berkaitan dengan ergonomi, dimana perlu untuk mendesain tempat wudhu yang ergonomi sehingga diharapkan kenyamanan saat berwudhu akan meningkat dan risiko cedera yang terjadi pada lansia akan berkurang. Karena gerakan fisik yang diulang-ulang namun tidak tidak mengacu pada prinsip ergonomi akan sangat rentan terkena cedera.
Berdasarkan uraian diatas penelitian tertarik untuk melakukan penelitian dengan tujuan: mendeskrisikan dan menguraikan desain tempat wudhu yang ergonomi terhadap lansia di Panyabungan, Mandailing - Natal.

\section{METODE}

Penelitian merupakan penelitian kualitatif dan dilakukan pada bulan Agustus 2021 Pengumpulan data menggunakan ATLAS.ti9 menggunakan pendekatan studi kasus. Desain wawancara digunakan untuk mendukung hasil penelitian tahap pertama. Informan penelitian ditentukan dengan purposive sampling terdiri dari informan kunci 3 orang lanjut usia, dan 1orang BKM masjid. Informan pendukung terdiri dari 1orang tokoh masyarakat, sehingga total informan 5 orang. Teknik pengumpulan data dalam penelitian ini yaitu dengan cara melakukan wawancara bebas terpimpin kepada informan dengan menggunakan teknik Miles dan Huberman dan melakukan pengamatan tempat wudhu di masjid Panyabungan, Mandailing-Natal. Tema yang didiskusikan antara lain: kenyamanan, keluhan, waktu berwudhu, frekuwensi menggunakan, dan kebutuhan fasilitas. Analisis data dilakukan dengan menggunakan software ATLAS.ti9 dengan menganalisis content pertanyaan informan. Validitas data dilakukan dengan 
menggunakan triangulasi sumber data yaitu: 1) sumber data diperoleh dari wawancara, 2) sumber data dari

\section{HASIL DAN PEMBAHASAN}

Data hasil wawancara terhadap tema disusun dalam transkip verbatim agar dapat dilakuka analisis. Proses analisis diawali dengan memberi kode, melakukan dokumentasi. Hasil frekuwensi dalam bentuk diagram tema, dan kesimpulan. telaah transkip, dan mencari pernyataan yang sesuai dengan kode, konsep dan hubungan. Hasil analisis menggunakan software ATLAS.ti9 sebagai berikut:

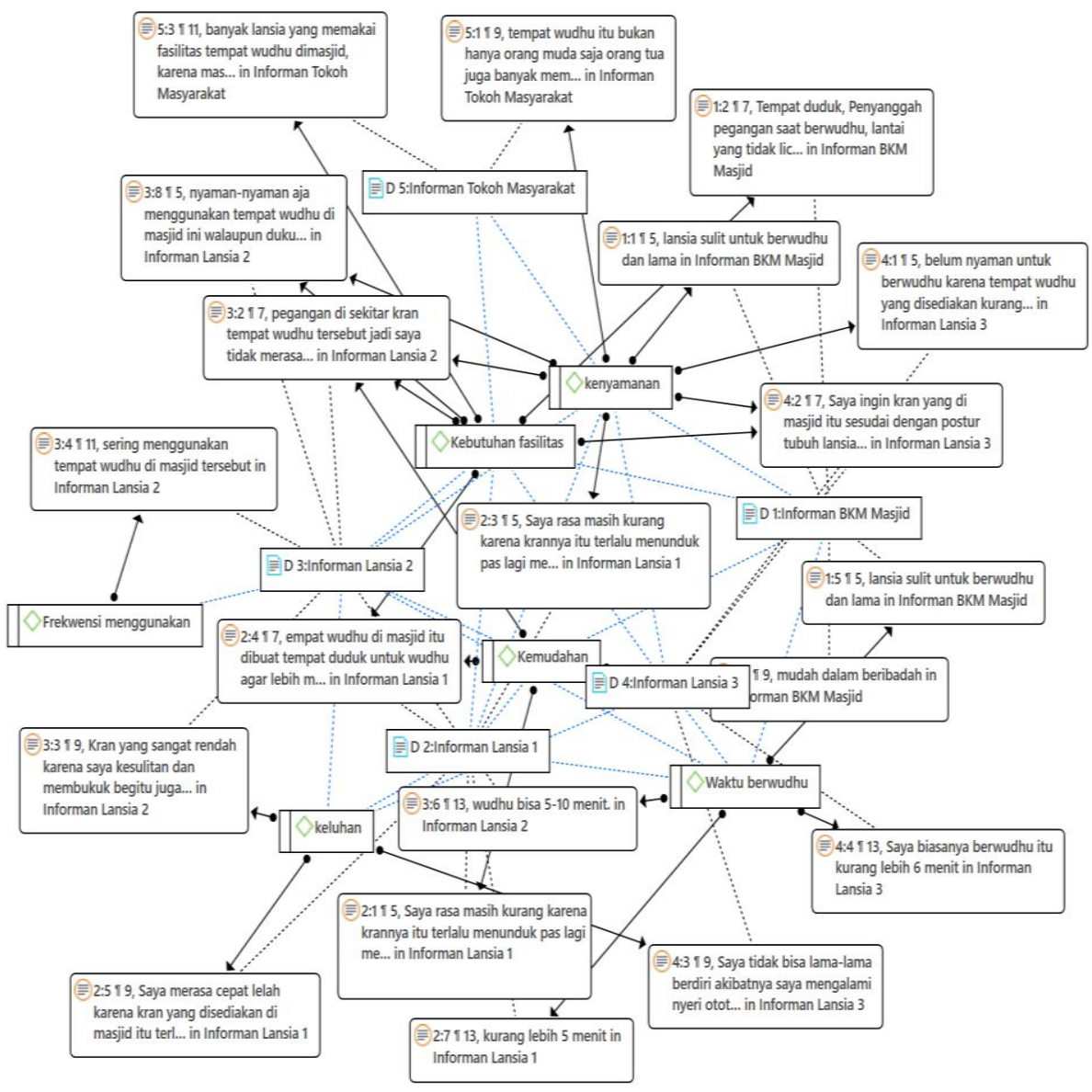

Gambar 1. Analisis Data Kualitatif menggunakan software ATLAS.ti9

Berdasarkan analisis ATLAS.ti9 yang ditunjukkan pada gambar diatas tersebut, dari 5 informan diperoleh 5 (code) tema yaitu: kenyamanan, keluhan, waktu berwudhu, frekuwensi menggunakan, dan kebutuhan fasilitas. 
Keunggulan analisis data kualitatif menggunakan ATLAS.ti9 diketahui koefisian korelasi antar tema (code), sehingga analisis data kualitatif mempunyai kesamaan dengan analisis data kuantitatif. Pola hubungan antar tema diketahui melalui analisis tabulasi silang code co-occurrence.

Hasil koefisien korelasi antar tema (code) diperlihatkan pada tabel berikut

Tabel 1. Nilai Co-occurrence

\begin{tabular}{|c|c|c|c|c|c|c|}
\hline Tema (kode) & $\begin{array}{c}\text { Frekuwensi } \\
\text { menggunakan }\end{array}$ & $\begin{array}{c}\text { Kebutuhan } \\
\text { fasilitas } \\
6\end{array}$ & $\begin{array}{l}\text { Keluhan } \\
3\end{array}$ & $\begin{array}{l}\text { Kemudahan } \\
4\end{array}$ & 7 & $\begin{array}{c}\text { Waktu } \\
\text { berwudhu }\end{array}$ \\
\hline $\begin{array}{c}\text { Frekuwensi } \\
\text { menggunakan }\end{array}$ & & & & & & \\
\hline 1 Kebutuhan & & & & $2(025)$ & $3(030) *$ & \\
\hline 6 Keluhan & & & & & & \\
\hline${ }_{4}^{3}$ Kemudahan & & $2(0,25)$ & & & $2(0,22)$ & \\
\hline${ }_{7}^{4}$ Kenyamanan & & $3(0,30) *$ & & $2(0,22)$ & & $\mathbf{1}(0,10)$ \\
\hline
\end{tabular}

Sumber: data primer, 2021 (*hubungan antar kode kuat)

Nilai Co-occurrence berada pada rentang 0-1 semakin mendekati satu maka mempunyai hubungan kuat. Table tersebut diketahui frekuwensi kemunculan quote mendekati satu maka menentukan kekuatan hubungan tema (kode). Nilai Cooccurrence yang tinggi adalah 0,30 berada pada table silang hubungan antara kenyamanan dengan kebutuhan fasilitas.

Melihat masjid sebagai bagian hasil kebudayaan masyarakat, maka tempat wudhu pun menjadi bagian dari sebuah budaya masyarakat. Seiring dengan kemajuan teknologi, maka tempat wudhu semakin memiliki banyak variasi. Beberapa aspek teknis yang mendapat perhatian dalam membangun sebuah temapat wudhu antara lain kenyamanan dan efesiensi pemanfaat air dengan tetap memperhatikan kaidah wudhu seperti yang telah disyari'atkan ajaran agama. Wudhu dilaksanakan melalui serangkaian gerakan tubuh.

Lanjut usia didefenisikan sebagai penurunan kelemahan, meningkatnya kerentanan terhadap berbagai penyakit dan perubahan lingkungan, hilangnya mobilitas dan ketangkasan, serta perubahan 
fisiologis yang terkait dengan usia. Secara kesehatan pada umumnya seseorang pada masa lanjut usia akan mengalami proses penuaan pada kondisi tubuhnya baik secara fisik, mental dan psikologi. Kondisi ini terjadi disebabkan oleh perubahan degenerative, yaitu perubahan secara keseluruhan pada tubuh meliputi jaringan dan sel, perubahan pada kulit, tulang, jantung, pembuluh darah, paru-paru, saraf dan jaringan tubuh lainnya (Kholifah, 2016).

Kemampuan fisik seseorang dicapai pada saat usianya antara 25-30 tahun, dan kapasitas fisiologi akan menurun $1 \%$ per tahunnya setelah kondisi puncaknya telampaui. Proses penuaan ditandai dengan tubuh yang melemah, gerakan tubuh makin lamban dan kurang bertenaga, keseimbangan tubuh semakin berkurang, dan makin menurunnya waktu reaksi (Saktiwan, 2010).

Menurut Saktiwan (2010) menjadi tua ditandai oleh kemunduran-kemunduran biologis terlihat sebagai gejala-gejala kemunduran fisik, antara lain: 1. Kulit mulai mengendur dan pada wajah timbul keriput serta garis-garis yang meneta 2 . Rambut mulai beruban dan menjadi putih 3. Gigi mulai ompong 4. Penglihatan dan pendengaran berkurang 5. Mudah lelah 6 . Gerakan menjadi lamban dan kurang lincah 7. Kerampingan tubuh menghilang, terjadi timbunan lemak terutama dibagian perut dan pinggul.

Tempat wudhu yang ergonomi sangat berpengaruh pada lansia karena ergonomi bertujuan untuk mendapatkan kesesuaian antara manusia dengan apa yang mereka lakukan, alat yang digunakan, dan lingkungan tempatnya berada. Dengan mendapatkan kesesuaian, manusia akan mendapatkan kenyamanan sehingga bisa menyelesaikan aktivitas dengan mudah dan cepat serta mengurangi kelelahan dalam melakukan aktivitas yang dikerjakan. Sugiono et al. (2018) menyatakan bahwa ergonomi mempunyai 3 tujuan yaitu, memberikan kenyamanan, kesehatan dan keselamatan kerja optimal, dan efesiensi kerja

Teori Mc Cormick menegaskan dalam membentuk kenyamanan sebuah produk atau rancangan fasilitas, perhatian pada faktor manusia (human faktor) berperan penting dalam menciptakan desain ergonomi yang baik, yang nantinya menciptakan kenyamanan bagi penggunanya .

Hasil penelitian ini menemukan 5 tema keluhan lanjut usia terhadap fasilitas tempat wudhu: frekuwensi penggunaan, kebutuhan fasilitas, kenyamanan, keluhan, dan waktu berwudhu, kebaruan dari penelitian ini berupa pengembangan kenyamanan melalui metode kualitatif yang belum dilakukan oleh penelitian lain. 
Menurut Suhardi et al. (2013) perancangan ulang terhadap fasilitas tempat wudhu yaitu, tahap penentuan solusi perancangan atas data keluhan dan keinginan, dan tahap penjelasan rancangan. Rancangan fasilitas tempat wudhu yang ergonomi mempunyai tujuan agar penggunaan fasilitas dalam melakukan aktivitas merasa nyaman serta terjamin keamanannya sehingga mampu menghasilkan produktivitas yang tinggi.

Menurut lansia yang saya wawancarai kondisi rancangan fasilitas tempat wudhu di masjid Panyabungan, Mandailing-Natal masih sangat minim terhadap ergonomi karena masih banyak lansia yang mengeluh dan kesulitan ketika berwudhu seperti, tinggi kran terlalu rendah sehingga lansia terlalu membungkuk,

sering tersandung akibat perbedaan ketinggian lantai, kesulitan keseimbangan ketika membasuh kaki, merasa cepat lelah dan tubuh tidak stabil pada posisi berdiri ketika wudhu. Oleh karen itu rancangan peralatan harus sesui dengan dimensi tubuh manusi.

Menurut penelitian Suhardi et al. (2013) untuk menjaga keseimbangan lansia ketika melakukan wudhu, maka tempat wudhu hasil rancangan diberi tambahan tempat duduk dan pijakan kaki. Dengan adanya tambahan tempat duduk dan pinjakan kaki, maka aktivitas wudhu bisa dilakukan dengan duduk. Sehinggan resiko terjatuh bisa dimunimalkan, penambahan hand rail sebagai alat bantu lansia digunakan untuk bangun dari posisi duduk, setelah selesai melakukan aktivitas wudhu. Tinggi kran juga disesuaikan dengan tinggi posisi duduk lansia sehingga lansia tidak membungkuk. Lantai antara tempat wudhu dan jalan dibuat rata dengan tujuan untuk meminimalkan resiko tersandung.

Menurut asumsi peneliti, kenyamanan merupakan proses interaksi lansia denganalat dan lingkungan sekitarnya merupakan bentuj keberhasilan karena fasilitas yang diberikan pada lansia mudah untuk digunakan. Kebutuhan fasilitas tempat wudhu yang ergonomic sangat berpengaruh pada lansia saat melakukan wudhu diantaranya: keluhan, kemudahan, dan waktu berwudhu. Fasilitas tempat wudhu yang ergonomic sangat diperlukan guna memperoleh desain tempat wudhu nyaman.

Menurut penelitian Suparwoko (2014), kenyamanan lansia dalam melakukan gerakan wudhu sangan ditentukan oleh tempat wudhu terutama faktor ketinggian kran, jarak antar kran wudhu, hand rail atau alat bantu manusia saat bangun dari posisi duduk, perbedaan ketinggian jalan dengan tempat wudhu dan posisi gerakan orang berwudhu dengan cara berdiri maupun duduk serta tipologi manusia yang melakukan kegiatan wudhu. 
Unsur yang penting diperhatikan dalam penelitian ini adalah hubungan antara lansia dengan fasilitas tempat wudhu yang disediakan. Satu sama lainnya saling berikteraksi dan memberi pengaruh signifikan terhadap penimgkatan produktivitas, efesien, keselamatan, kesehatan, kenyamanan maupun ketenagan dalam melakukan aktivitas sehingga dapat menghidari dari kecelakaan. Menurut peneliti, tempat wudhu duduk pada lansia sangat berpengaruh pada produktivitas dan kemudahan lansia salam berwudhu, ketinggian kran juga dapat menciptakan kenyamanan berwudhu pada lansia karena posisi kran yang terlalu tinggi akan menimbulkan lebih banyak cipratan air sehingga berpotensi mengotori pakaian pengguna tempat wudhu, sementara posisi kran yang terlalu rendah mengharuskan pengguna tempat wudhu membungkuk terlalu dalam sehingga menggagu kenyamanan saat berwudhu.

Menurut Sugiyono (2018), berdasarkan uraian diatas dapat disimpulkan bahwa ergonomic merupakan suatu bidang keilmuan tentang cara menyerasikan antara manusia dengan lingkunagannya agar terciptanya kenyamanan, keselamatan dan

\section{KESIMPULAN DAN SARAN}

\section{Kesimpulan}

Kesimpulan yang dapat diambil dari penelitian ini, sebagai berikut: dari analisis pencegahan terhadap timbulnya cidera ataupun gangguan kesehatan dengan tujuan meningkatkan produktivitas dan kualitas hidup manusia dan dapat diintrepretasikan bahwa pusat dari ergonomic adalah manusia.

Menurut peneliti, kesejahteraan lansia juga perlu diperhatikan dalam bentuk fasilitas karena lansia juga membutuhkan alat yang bisa dipakai dan mempermudah dalam beraktivitas salah satunya adalah menyediakan tempat wudhu yang ergonomi pada lansia.

Penelitian yang sebelumnya dilakukan Mulyono et al. (2013), membahas mengenai ergonomi tempat duduk pada sebuah universitas dengan objek peneliti orang dengan kelebihan berat badan kemudian penelitian tentang ergonomi tempat wudhu adalah Suparwoko (2014), yang membahas tentang standard dan desain tempat wudhu dalam tata ruang masjid dengan pendekatan ergonomis dan efesien air dengan objek penelitian masyarakat setempat, sedangkan Suparwoko (2016), hasil penelitiannya menekankan pada aspek tata runag dan ukuran yang digunakan dengan analogi berdasarkan rancanagan yang telah ada.

didapatkan bahwa tempat wudhu dengan posisi duduk mempunyai nilai terbaik didalam penelitian ini, Kebutuhan fasilitas mempengaruhi kenyamanan berwudhu 
pada lansia, Lantai pada tempat wudhu dibuat rata dengan jalan.

Saran

Saran dari penelitian yang didapat peneliti ini adalah:

1. Perlunya pijakan kaki, pegangan tangan dan ketinggian kran yang baik untuk dipasan di tempat wudhu posisi berdiri

2. Perlunya tempat wudhu dengan posisi duduk untuk disediakan pada tempat wudhu masjid Panyabungan, MandailingNatal, karena tempat wudhu dengan posisi duduk lebih baik dibandingkan dengan tempat wudhu posisi berdiri

\section{DAFTAR PUSTAKA}

Azizah, L. M. (2011). Keperawatan Lanjut Usia (1 ed.). Graha ilmu.

Festi, P. (2018). Lanjut Usia Perspektif dan Masalah (D. Nasrullah (ed.)). UMSurabaya Publishing. https://www.google.co.id/books/editi on/Lanjut_Usia_Perspek

Isywari, S. R., \& Iskandriawan, B. (2016). Desain Alat Exercise Ringan guna Mengisi Waktu Luang Lansia dalam Upaya Menjaga Kondisi Kesehatan Fisik dan Psikis. Sains dan Seni, 5. https://media.neliti.com/media/public ations/133938-ID-desain-alatexercise-ringan-guna-mengisi.pdf

Kementerian Kesehatan RI. (2017). Analisis Lansia di Indonesia. In
Pusat Data dan Informasi. Kementerian Kesehatan RI.

Kholifah, S. N. (2016). Keperawatan Gerontik (Kementerian Kesehatan RI (ed.)). Pusat Pendidikan Sumber Daya Manusia Kesehatan Badan Pengembangan dan Pemberdayaan Sumber Daya Manusia Kesehatan.

Mulyono, Hamzah, M. ., \& A.z, A. (2013). faktor yang berpengaruh terhadap kinerja perawat di rumah sakit tingkat III 16.16.06.01 Ambon. AKK, 2(1).

Saktiwan, P. (2010). PERANCANGAN ULANG TEMPAT WUDHU UNTUK LANJUT USIA (LANSIA) (Studi kasus Panti Wredha Dharma Bakti Surakarta). Sebelas Maret.

Sugiono, Wisnu, P. W., \& Sylvie, I. (2018). Ergonomi Untuk Pemula Prinsip Dasar dan Aplikasinya (M. Ali (ed.); Cetakan Pe). UB Press. https://books.google.co.id/books?hl= en\&lr=\&id=4QKGDwAAQBAJ\&oi= fnd \&pg=PR $5 \& d q=$ ergonomi $+\&$ ots $=$ ZfF3zdkoSB\&sig=8I7ipmk2Ee7NIjK I4e9nizqGXT0\&redir_esc $=y \# v=o n e p$ age $\& \mathrm{q}=$ ergonomi $\& \mathrm{f}=$ false

Sugiyono. (2018). Metode Penelitian Kuantitatif Kualitatif dan $R \& D$ (Sutopo (ed.); 1 Cek 1 s.). Alfabeta. Suhardi, B., Laksono, P. W., \& Saktiwan, P. (2013). Perancangan Tempat Wudhu Untuk Orang Lanjut Usia (Lansia). Ergonomi for Special Need. 
Suparwoko. (2014). Standar dan Desain

Tempat Wudhu Dalam Tata Ruang

MAsjid dengan Pendekatan

Ergonomis dan Efesien Air (Sobirin

Ma). Total Media.

Suparwoko, W. (2016). Perancangan

Tempat Wudhu dan Tata Ruang

Masjid. Total Media. 